Supporting Information

\title{
2D layered $\mathrm{Co}(\mathrm{OH})_{2} / \mathrm{g}-\mathrm{C}_{3} \mathrm{~N}_{4} / \mathrm{Ni}(\mathrm{OH})_{2}$ ternary nanocomposite
}

\section{for enhanced visible-light photocatalytic $\mathbf{H}_{2}$-production activity}

\author{
Jun Zhang ${ }^{\mathrm{a}}$, Shuai Shao ${ }^{\mathrm{a}}$, Desen Zhou ${ }^{\mathrm{a}}$, Tingmin $\mathrm{Di}^{\mathrm{b}}$ and Tielin Wang*a \\ ${ }^{a}$ Key Laboratory of Green Chemical Process of Ministry of Education, Key Laboratory of Novel Reactor and \\ Green Chemical Technology of Hubei Province, School of Chemical Engineering and Pharmacy, Wuhan Institute \\ of Technology, Wuhan 430205, P. R. China. \\ b School of Materials Science and Engineering, Wuhan Institute of Technology, Wuhan 430205, P. R. China.
}

*Corresponding author:

E-mail: witwangtl@hotmail.com (T. L. Wang); junzhang@wit.edu.cn (J. Zhang) 


\section{Characterization}

The crystalline phases of the obtained samples were recorded on X-ray diffraction (XRD) by an X-ray diffractometer (Rigaku, Japan) using $\mathrm{Cu} \mathrm{K}$ radiation $(\lambda=0.15418 \mathrm{~nm})$ at a scan rate $(2 \theta)$ of $0.05^{\circ} \mathrm{s}^{-1}$. The morphology of the samples was characterized by field emission scanning electron microscopy (FESEM) on JSM-7500 electron microscope (JEOL, Japan) operating at an accelerating voltage of $15 \mathrm{kV}$. Morphological observation was further visualized by the transmission electron microscopy (TEM) on a Tecnai $\mathrm{G}^{2}$ F20 S-TWIN microscope with a field emission gun at a $200 \mathrm{kV}$ accelerating voltage. UV-vis diffuse reflectance spectra were investigated by a UV-vis spectrophotometer (UV-2600, Shimadzu, Japan) using $\mathrm{BaSO}_{4}$ powder as a reference standard. The Brunauer-Emmett-Teller (BET) surface area was carried by Micromeritics ASAP 2020 nitrogen adsorption apparatus (USA). All the samples were degassed at 150 ${ }^{\circ} \mathrm{C}$ before nitrogen adsorption measurements. The BET specific surface area was tested by a multipoint BET method using the adsorption data in the relative pressure $\left(P / P_{0}\right)$ range of $0.05-0.25$. The pore size distributions were measured utilizing desorption data by the Barrett-Joyner-Halenda (BJH) method. The pore volume and average pore size was determined by the nitrogen adsorption volume at the relative pressure $\left(P / P_{0}\right)$ of 0.972 . X-ray photoelectron spectroscopy (XPS) measurements were operated by an ultrahigh-vacuum VG channel detector. The spectra were excited using $\mathrm{Al} \mathrm{K}_{\alpha}(1486.7 \mathrm{eV})$ radiation (operated at $300 \mathrm{~W}$ ) of a twin anode in the constant analyzer energy mode with an energy of $30 \mathrm{eV}$. Photoluminescence (PL) emission spectra were obtained on a Fluorescence Spectrophotometer (F-7000, Hitachi, Japan) with the excitation of $350 \mathrm{~nm}$. Time-resolved fluorescence emission spectra were surveyed by a FLS920 fluorescence lifetime spectrophotometer (Edinburgh Instruments, UK) with the excitation of $375 \mathrm{~nm}$ and the detection wavelength of $540 \mathrm{~nm}$ using silica gel as the reference standard.

\section{Photoelectrochemical measurements}

Electrochemical measurements were performed on an electrochemical analyzer (CHI660C Instruments). The conventional three-electrode system used the prepared samples on F-doped tin oxide coated glass (FTO 
glass) as the working electrodes, platinum wire as the counter electrode and $\mathrm{Ag} / \mathrm{AgCl}$ (saturated $\mathrm{KCl}$ ) as the reference electrode. A $300 \mathrm{~W}$ Xe arc lamp was served as the illumination while $0.5 \mathrm{M} \mathrm{Na}_{2} \mathrm{SO}_{4}$ solution was used as the electrolyte. The working electrode was fabricated as follows: $0.080 \mathrm{~g}$ of specimen was ground with $0.032 \mathrm{~g}$ of polyethylene glycol (PEG) and $1 \mathrm{~mL}$ of ethanol to make a slurry compound. Then the slurry was coated onto a $2 \mathrm{~cm} \times 1.2 \mathrm{~cm}$ FTO glass electrode by the doctor blade method. After these electrodes were dried, they were calcinated at $450{ }^{\circ} \mathrm{C}$ for $30 \mathrm{mins}$ to improve adhesion. All test electrodes have a similar film thickness $(10 \sim 11 \mu \mathrm{m})$.

\section{Photocatalytic $\mathbf{H}_{2}$-production activity}

The photocatalytic hydrogen evolution reactions were performed in a $100 \mathrm{~mL}$ Pyrex flask at ambient temperature and atmospheric pressure, the reactor was connected to a closed gas circulation and evacuation system. A $300 \mathrm{~W}$ Xe arc lamp through a UV-cutoff filter $(\leq 420 \mathrm{~nm})$ was used as light source. The focused intensity on the flask was $c a .150 \mathrm{~mW} / \mathrm{cm}^{-2}$. In a typical photocatalytic hydrogen production experiment, 50 mg of sample powder was immersed in $80 \mathrm{~mL}$ of $10 \mathrm{vol} \%$ triethanolamine aqueous solution and scattered in ultrasonic bath for several minutes to obtain a uniform solution. Before irradiation, the suspension was bubbled with nitrogen for 30 minutes to entirely remove the dissolved oxygen and ensure the laboratory reactor was in an anaerobic environment. Continuous magnetic stirring was running at the bottom of the reactor to ensure the photocatalyst particles in suspension during the course of reactions. A $0.4 \mathrm{~mL}$ gas was intermittently sampled through the septum, and $\mathrm{H}_{2}$ content was determined by gas chromatography (GC14C, Shimadzu, Japan, TCD, with nitrogen as a carrier gas and $5 \AA$ molecular sieve column). 


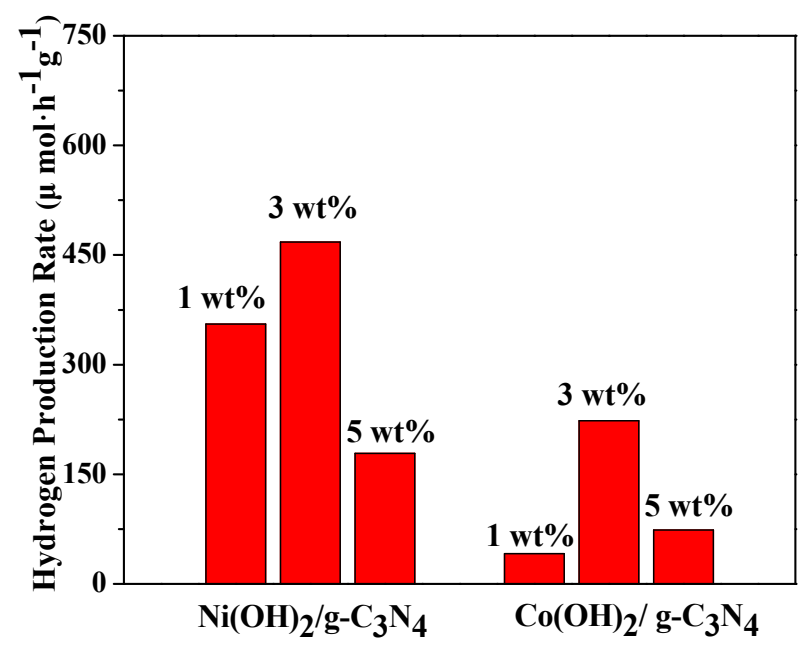

Fig. S1 Comparison of the $\mathrm{H}_{2}$ production rates of different content of $\mathrm{Ni}(\mathrm{OH})_{2}$ and $\mathrm{Co}(\mathrm{OH})_{2}$ for $\mathrm{Ni}(\mathrm{OH})_{2} / \mathrm{g}-\mathrm{C}_{3} \mathrm{~N}_{4}$ and $\mathrm{Co}(\mathrm{OH})_{2} / \mathrm{g}-\mathrm{C}_{3} \mathrm{~N}_{4}$ samples.
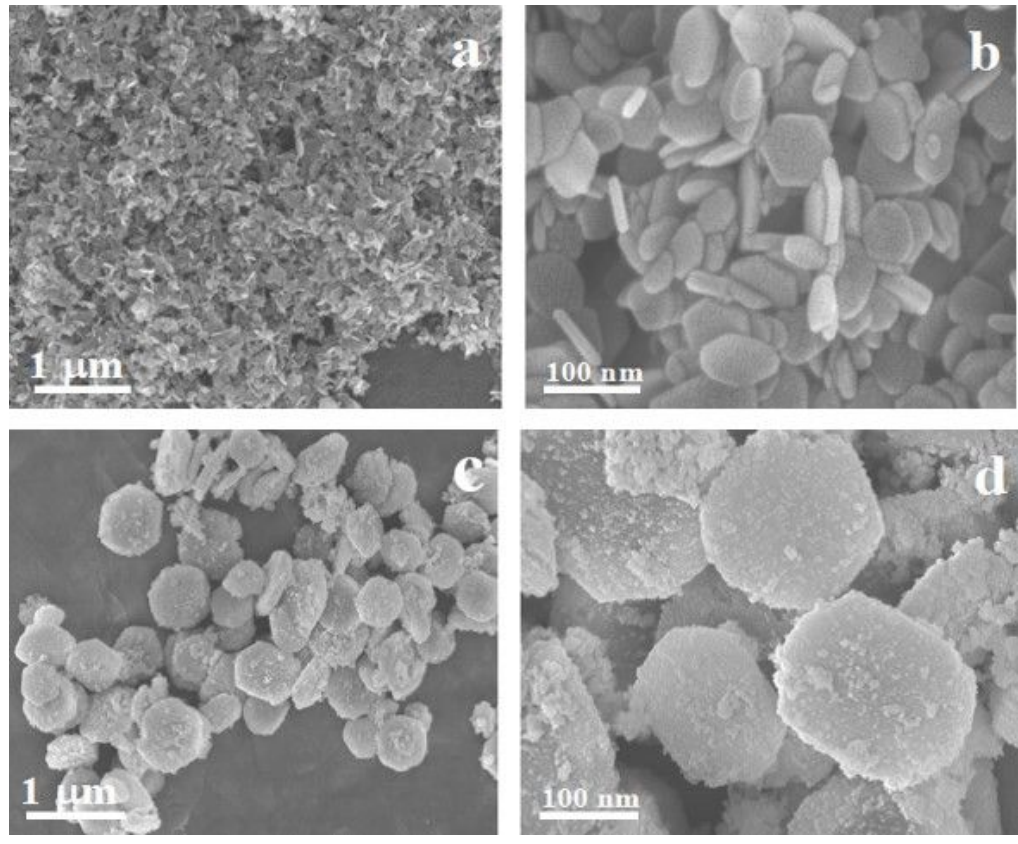

Fig. S2 FESEM images of pure $(\mathrm{a}, \mathrm{b}) \mathrm{Ni}(\mathrm{OH})_{2}$ and $(\mathrm{c}, \mathrm{d}) \mathrm{Co}(\mathrm{OH})_{2}$ nanosheets. 


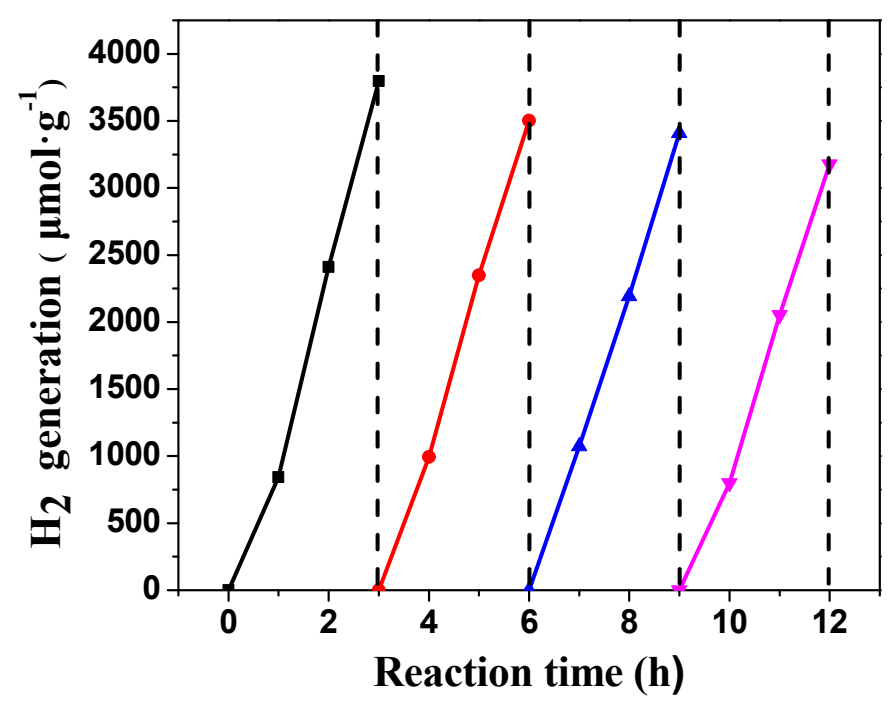

Fig. S3 Time course of photocatalytic $\mathrm{H}_{2}$-produciton over NCC sample, every three hours the reaction system is bubbled with $\mathrm{N}_{2}$ for 30 min to remove the $\mathrm{H}_{2}$ inside. 